\title{
Polypropylene/ethylene-propylene rubber (PP/EPR) blends for the automotive industry: Basic correlations between EPR-design and shrinkage
}

\author{
G. Grestenberger*, G. D. Potter, C. Grein ${ }^{+}$ \\ Borealis Polyolefine GmbH PO R\&, St.-Peter-Strasse 25, A-4021 Linz, Austria \\ ${ }^{+}$Present address: SABIC Europe, P.O. Box 5151, 6130 PD Sittard, The Netherlands
}

Received 22 July 2013; accepted in revised form 14 December 2013

\begin{abstract}
The influence of the phase morphology on the shrinkage of injection molded plates from reactor based PP/EPR blends was investigated using a model series. The morphology of the dispersed phase - in terms of size and shape of the rubber particles as determined from scanning electron microscopy (SEM) - was found to correlate fairly well with the shrinkage determined in the flow and transverse direction of injection molded plates. In this respect it turned out to be elementary to consider the anisotropy of the particles rather than their average size alone. Additionally, the effect of the EPR design on the coefficient of linear thermal expansion (CLTE) was evaluated and brought into a relationship with the blend morphology.
\end{abstract}

Keywords: polymer blends, polypropylene, morphology, injection molding

\section{Introduction}

Automotive parts like bumpers, body panels, dashboards and door claddings are nowadays made out of advanced polypropylene (PP) materials. Most of the time, heterophasic blends - where PP is the continuous phase and an ethylene-propylene copolymer (EPR) the dispersed one - are used. The polypropylene matrix delivers the stiffness of the material whereas the rubbery inclusions act as impact modifiers providing a grade with balanced stiffness-impact behavior. Besides this basic requirement, getting a low shrinkage (i.e. a very limited difference between mold and part geometry) and a low thermal expansion is also more and more targeted. The latter is especially relevant when polymer parts are combined with metal parts which will normally have a significantly lower thermal expansion in the application temperature range.
Shrinkage is not an intrinsic material property, but rather a result of the thermal and mechanical conditions a material experiences during processing. The main factors that influence the shrinkage of the final part are the polymer itself, the processing parameters, the mold design and the geometry of the molded part.

Most studies concerning post-molding shrinkage of polypropylene (PP) parts focus on the influence of molding parameters (temperature and speed), geometry and mold design [1-5], very often using only one defined polymer for performing the study. One of the earliest extensive studies regarding molecular structure and polymer composition effects on the shrinkage of PP was done by Fujiyama and Kimura [6], in which both the general reduction of shrinkage with increasing melt flow rate (MFR) and the additional shrinkage-reducing effect of elastomer

\footnotetext{
${ }^{*}$ Corresponding author, e-mail: georg.grestenberger@borealisgroup.com (C) BME-PT
} 
particles and filler became apparent already. For PP homopolymers, these studies were later expanded to variations of molecular weight distribution (MWD) and isotacticity [7] to show a massive effect of MWD polydispersity on morphology (skin layer formation) and shrinkage.

When more complex compositions involving elastomer and filler components have to be considered, the contributions of the various components to shrinkage were analyzed (e.g. Pantani and Titomanlio [8]), finding reasonable agreements for a volumebased addition approach in model experiments. While platy mineral particles like talc have been found to have a stabilizing effect, reducing the shrinkage in a rather isotropic manner [9], fibrillar or acicular particles like glass fibers or multi-walled carbon nanotubes (MWNT) will certainly increase shrinkage anisotropy due to their high degree or orientation in flow direction during mold filling [10]. In addition to the composition, the testing time for shrinkage also needs to be considered, as different polymer compositions and/or processing parameter sets will generate different time dependences of shrinkage $[3,11]$.

The number of studies dealing with the thermal expansion of PP parts which is frequently expressed as the coefficient of linear thermal expansion (CLTE) is significantly lower than for shrinkage. The morphology plays a decisive role, even more than for the case of shrinkage, on top of the component contributions as demonstrated in the work of Ono and coworkers $[12,13]$. The development of highly oriented elastomer arrays or networks through the selection of a suitable viscosity ratio can quite obviously reduce expansion significantly. Especially in combination with a modification by solid micro- or nanoparticles [14], the interactions can become very complex as these particles will in turn modify the phase morphology.

Hence, the present study aims to evaluate the influence of the phase morphology on the shrinkage and CLTE (coefficient of linear thermal expansion) of PP/EPR blends. For this purpose, in-reactor made heterophasic copolymers have been investigated and key morphology drivers were varied systematically based on earlier experience in polymer development.

\section{Experimental}

\subsection{Materials}

A set of eight in-reactor made heterophasic copolymers with a systematic variation in molecular weight of the rubber portion at comparable EPR compositions were polymerized in lab scale (Table 1 and Table 2). To evaluate the effect of matrix crystallinity, both a series with and without in-reactor nucleation were prepared.

These materials were polymerized in a multi-stage process using a $4^{\text {th }}$ generation Ziegler-Natta catalyst supported on $\mathrm{MgCl}_{2}$ in combination with a silane donor and triethyl-aluminum as an activator/scavenger. For the in-reactor nucleated versions, the catalyst system further contained isotactic poly(vinyl cyclohexane) (PVCH) as a polymeric nucleating agent. PVCH is effective at already very low loadings $(<100 \mathrm{ppm})$ and, compared to other external nucleating agents, shows clear advantages in terms of mechanical and optical properties $[15,16]$.

In particular, the investigated heterophasic copolymers consist of an isotactic PP homopolymer matrix with a Melt Flow Rate (MFR) of $\sim 40 \mathrm{~g} / 10 \mathrm{~min}$ (ISO $1133,230^{\circ} \mathrm{C} / 2.16 \mathrm{~kg}$ ) and about $29 \mathrm{wt} \%$ of an ethylene-propylene copolymer (EPR). Apart from the molecular weight of the EPR phase, all other polymer parameters were kept rather constant throughout the series. Since the investigated materials have been produced in a two stage polymerization process, the EPR phase is not accessible independently. Therefore, the xylene cold soluble (XCS) fraction (determined acc. ISO 6427-1992) was assumed to represent the EPR phase. The average molecular weight of the rubber (EPR) fraction was

Table 1. Material composition parameters of non-nucleated samples

\begin{tabular}{|l|r|r|r|r|}
\hline & IV 1.5 & IV 1.9 & IV 2.2 & IV 2.5 \\
\hline XCS-content [wt\%] & 29.2 & 31.2 & 31.5 & 31.7 \\
\hline $\mathrm{C}_{2}$-content of XCS [wt \%] & 34.4 & 34.6 & 34.3 & 33.4 \\
\hline IV of XCS [dL/g] & 1.5 & 1.9 & 2.2 & 2.5 \\
\hline MFR $[\mathrm{g} / 10 \mathrm{~min}]$ & 27.2 & 19.4 & 16.3 & 14.4 \\
\hline
\end{tabular}

Table 2. Material composition parameters of in-reactor nucleated samples

\begin{tabular}{|l|r|r|r|c|}
\hline & IV 1.5N & IV 1.9N & IV 2.2N & IV 2.5N \\
\hline XCS-content $[\mathrm{wt} \%$ ] & 27.9 & 29.0 & 29.4 & 27.6 \\
\hline $\mathrm{C}_{2}$-content of XCS [wt\%] & 36.2 & 36.3 & 36.5 & 34.2 \\
\hline IV of XCS [dL/g] & 1.5 & 1.9 & 2.2 & 2.5 \\
\hline MFR [g/10 min] & 27.1 & 20.6 & 17.1 & 14.7 \\
\hline
\end{tabular}


assessed by intrinsic viscosity (IV) measurements of the XCS fraction (ISO $1628-1$, decaline at $135^{\circ} \mathrm{C}$ ) and varied between 1.5 and $2.5 \mathrm{dL} / \mathrm{g}$.

The comonomer (ethylene) content was determined by quantitative Fourier transform infrared spectroscopy (FTIR) after basic assignment calibrated via quantitative ${ }^{13} \mathrm{C}$ nuclear magnetic resonance (NMR) spectrometry in a manner well known in the art. Thin films were pressed from the XCS fraction to a thickness of $\sim 300 \mu \mathrm{m}$ and spectra recorded in transmission mode. Specifically, the ethylene content of the EPR was determined using the baseline corrected peak area of the quantitative bands found at $720-722$ and $730-30733 \mathrm{~cm}^{-1}$. Quantitative results were obtained based upon reference to the film thickness, and the ethylene content of the XCS fraction was $35 \pm 1.5 \mathrm{wt} \%$ for all materials.

\subsection{Dimensional stability}

\subsubsection{Shrinkage}

Shrinkage was determined on injection molded quadratic plaques of $60 \times 60 \times 2 \mathrm{~mm}^{3}$. The film gated specimens were produced on an Engel V60 injection molding machine. The following process parameters were applied: $200^{\circ} \mathrm{C}$ melt temperature, $100 \mathrm{~mm} / \mathrm{s}$ flow front velocity (inside the mold), 10 seconds holding pressure time and 10 bars hydraulic holding pressure level. The dimensions (length and width) of the plaques were determined with a digital measuring slide and compared to the dimensions of the cavity at room temperature about (but not less than) $96 \mathrm{~h}$ after de-molding.

\subsubsection{Coefficient of linear thermal expansion (CLTE)}

CLTE measurements were done at Johannes Kepler University Linz (Institute of Polymer Science) in accordance with DIN 53752 on $10 \times 10 \times 4 \mathrm{~mm}^{3}$ specimen prepared from injection molded test bars $(80 \times$ $10 \times 4 \mathrm{~mm}^{3}$ ). These test bars are normally used for assessment of Charpy impact strength according to ISO 179 and the central portion of the bars is cut and polished for the CLTE measurements. The thermal expansion in flow direction was monitored in a temperature range from $-30^{\circ} \mathrm{C}$ to $+80^{\circ} \mathrm{C}$. The average CLTE on a given temperature range $\left(\alpha_{\mathrm{T}_{1} / \mathrm{T}_{2}}\right)$ is defined by Equation (1):

$\alpha_{\mathrm{T}_{1} / \mathrm{T}_{2}}=\frac{1}{L} \cdot \frac{L_{2}-L_{1}}{T_{2}-T_{2}}$ where $L, L_{1}$ and $L_{2}$ are resp. the reference length determined at $23^{\circ} \mathrm{C}$, the length measured at temperature $T_{1}$ and the length at temperature $T_{2}$.

\subsection{Scanning electron microscopy (SEM)}

For morphology investigations the shrinkage specimens as defined above were cut perpendicular to the flow direction. The surface of the specimens was prepared with an ultra-cryo-microtome (PMC PCPT). To increase the contrast between matrix and rubber phase the samples were etched in n-heptane at room temperature over night ( $\sim 14$ hours). n-heptane dissolves the amorphous EPR-inclusions but hardly affects the semi-crystalline PP matrix. Holes are created in the samples surface due to the removal of the EPR particles. These holes appear as dark regions in the SEM image allowing an evaluation of the dispersed phase morphology. Following this procedure SEM micrographs were taken from the skin to the core of the specimen in order to assess and quantify the changes in particle size and shape over the thickness. The SEM investigations were done with a FEI Quanta 200 FEG microscope at an acceleration voltage of $5.0 \mathrm{kV}$ and various magnifications $(1,000-30,000 \times)$.

\section{Results and discussion \\ 3.1. Morphology}

From the overview of SEM images in Figure 1, it is obvious that the particle size of the dispersed EPR phase is affected significantly by the molecular weight of the EPR phase. As both matrix viscosity and the composition of the EPR is similar for all samples the phase viscosity ratio between matrix and rubber can be assumed to be the driving force for this development [17-22].

For heterophasic polymer systems like the investigated ethylene-propylene copolymers (also termed rTPOs for 'reactor thermoplastic polyolefins') the viscosity ratio $\lambda$ between dispersed phase and matrix phase is known to control the final morphology. The ratio in dynamic viscosity between rubber and matrix at a defined shear rate is considered for the calculation of $\lambda$ (e.g. compare [17] and [18]), as shown by Equation (2):

$\lambda=\frac{\eta_{\mathrm{d}}^{*}}{\eta_{\mathrm{m}}^{*}}$

For a first approximation and in lack of viscosity data from dynamic measurements, $\lambda$ can also be 


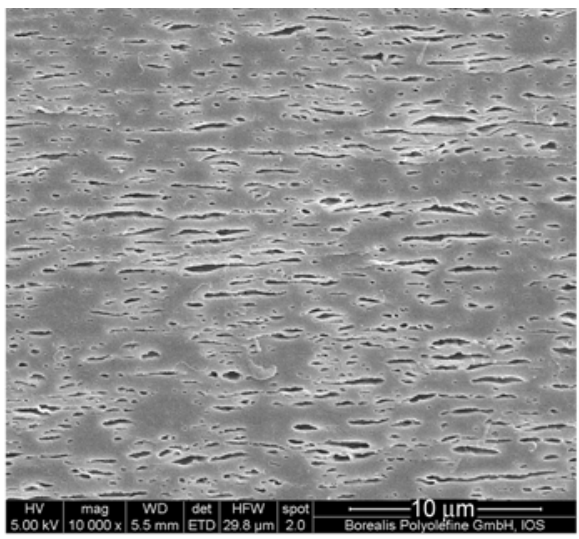

a)

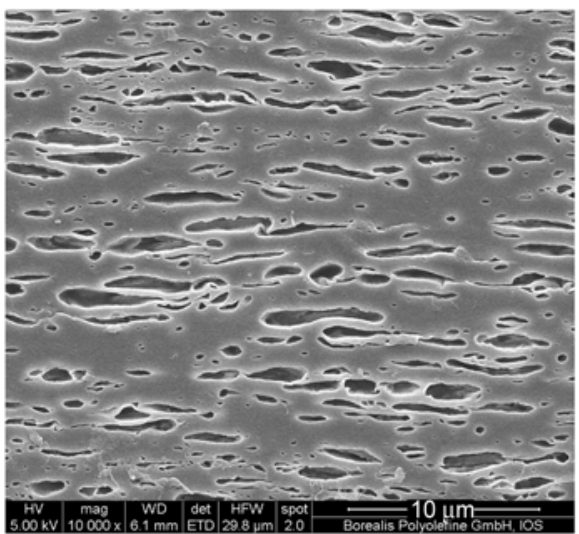

b)

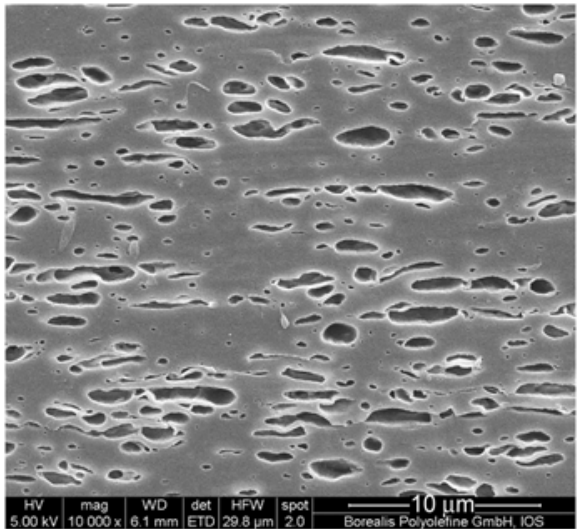

c)

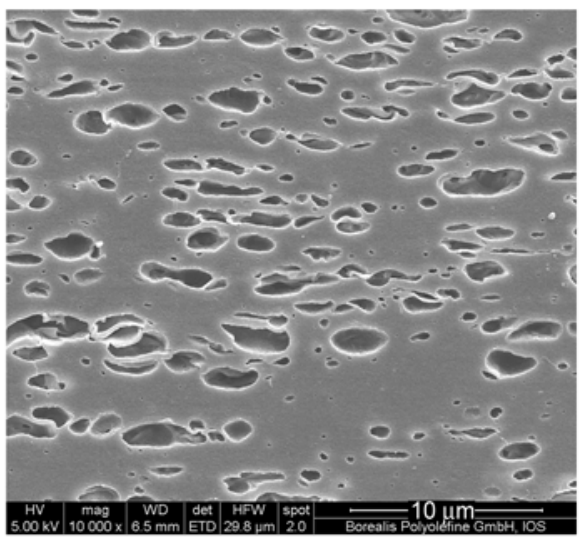

d)

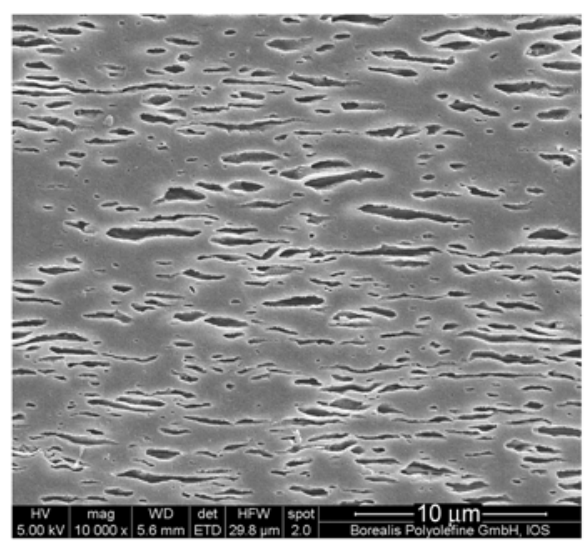

e)

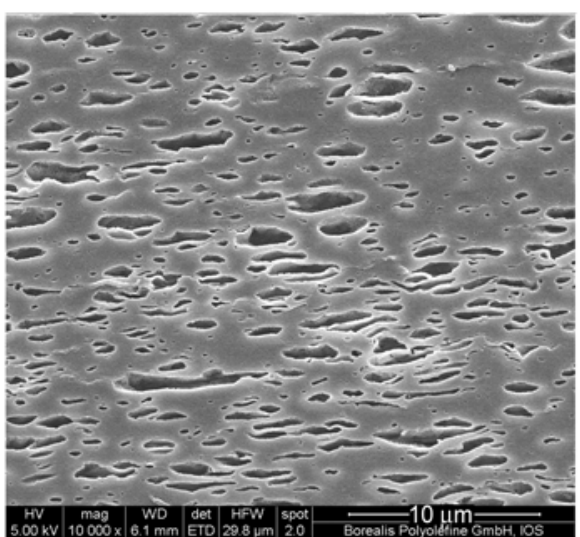

f)

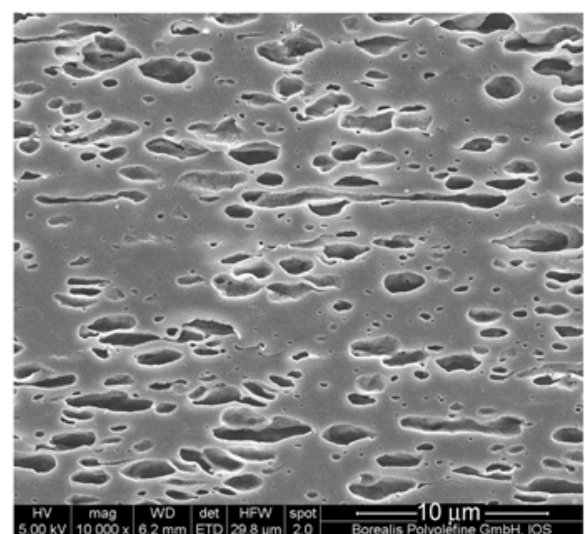

g)

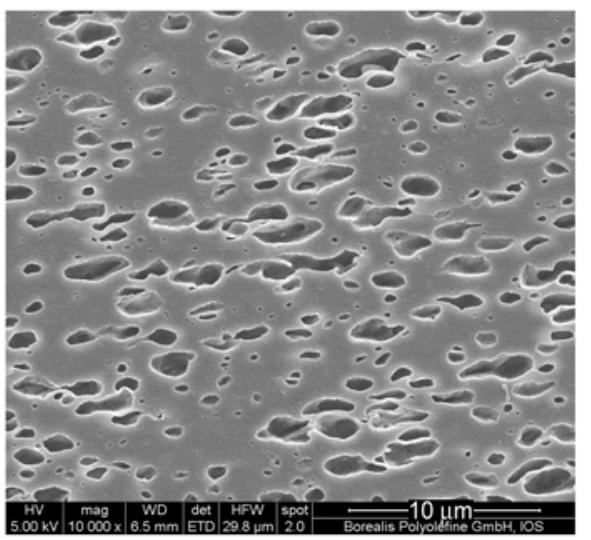

h)

Figure 1. SEM-images of the investigated plates taken at different distances from the surface of the samples: IV(XCS) 1.51.9-2.2-2.5 from top to bottom, skin layer at $100 \mu \mathrm{m}$ below surface left column a-d, core layer at $1000 \mu \mathrm{m}$ below surface right column e-h; MD perpendicular to image plane, TD horizontal, ND vertical). 
determined by the ratio in intrinsic viscosity between dispersed phase $I_{d}$ and matrix phase $I V_{m}$ (e.g. compare [18] and [19], see Equation (3)), provided that relative rather than absolute values are targeted:

$\lambda=\frac{\mathrm{IV}_{\mathrm{d}}}{\mathrm{IV}_{\mathrm{m}}}$

While the final phase morphology may be affected by the processing step, the particle size distribution (PSD) is mostly defined by particle break-up and aggregation during the melt mixing (compounding or pelletization) step [21]. In this respect, the initial particle size expressed by the radius $R$, the interfacial tension $\alpha$ between the phases and the actual shear rate $\gamma^{*}$ control the dispersion process in this melt mixing step. Particle deformation and break up only occurs if the according Equation (4) calculated Weber number is larger than a critical value [18].

$W e=\frac{\gamma^{*} \eta_{\mathrm{m}} \cdot R}{\alpha}$

This effect has not being considered quantitatively in the current investigation due to a lack of experimental data for radius $R$ and interfacial tension $\alpha$.

In earlier studies, the various averages of the same PSD have been related to the melt viscosity ratio and/or the compatibility between the phases, often expressed by the interfacial tension $\alpha$. Wu [23] as well as Serpe et al. [24] have investigated blend combinations with high chemical diversity and consequently high interfacial tensions e.g. nylon and polyester as the matrix and EPR as the dispersed phase. More relevant for the present study, in which matrix and disperse phase are very similar, are papers like the ones by Mighri et al. [25] and Kock et al.

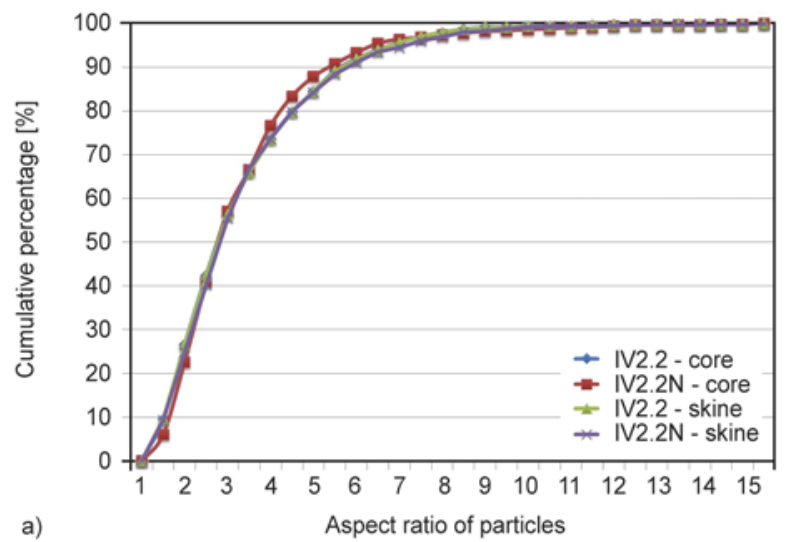

[26]. None of these studies investigated reactorbased heterophasic systems like the ones in this study. Common to all these works is the fact that for reliable results relaxed specimens are necessary to determine equilibrium PSDs with spherical EPR particles.

From the SEM images the size distribution (PSD) of the dispersed EPR particles was determined by means of Image J (V1.43), a public domain Java image processing and analysis software [27]. Since the morphology of the dispersed phase is believed to be only marginally affected by an additional alpha nucleation, SEM images were taken from the nucleated materials only. The validity of this assumption was proven by comparing the morphologies of samples IV2.2 and IV2.2N (Figure 2). It can consequently be assumed that nucleation will affect shrinkage and CLTE largely independent of the phase morphology.

The morphology images were reworked manually before analyzing the size and shape of the EPR particles. This was inevitable since the contrast between the dark areas (holes where the EPR was extracted) and the matrix phase was too low to allow an automated detection of the phase boundaries via Image J. In a subsequent step, the manually contrasted images were converted into binary images (i.e. converted into black and white images). All particles at the edges of the image where excluded from the analysis to avoid misinterpretation of the data. Furthermore, a minimum particle size of $0.05 \mu \mathrm{m}^{2}$ was defined in order to remove speckles and noise in the pictures.

Assuming spherical particles for the sake of PSD, the average particle diameters in number $D_{\mathrm{n}}$, in weight

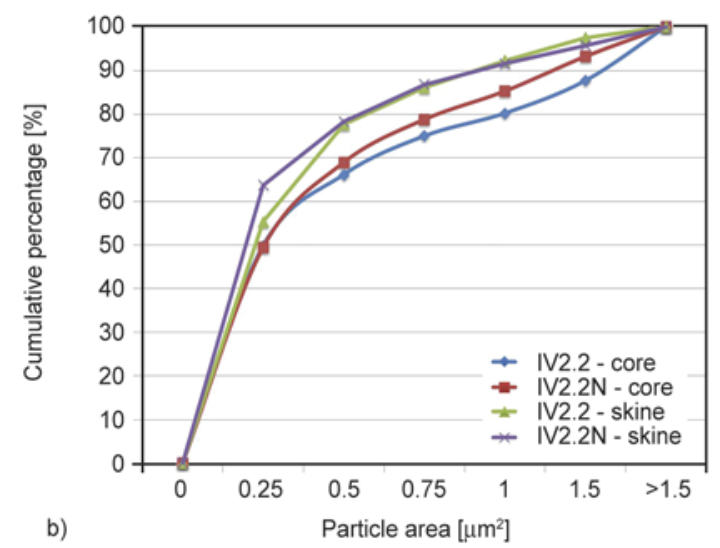

Figure 2. Distribution of particle aspect ratio (a) and particle size (b) for the nucleated and non-nucleated version of sample IV 2.2 
$D_{\mathrm{w}}$ and in volume $D_{\mathrm{v}}$ were evaluated according to [19] and [20] as Equation (5):

Average particle diameters in number $D_{\mathrm{n}}$

$$
D_{\mathrm{n}}=\frac{\sum_{\mathrm{i}=1}^{\mathrm{N}} n_{\mathrm{i}} D_{\mathrm{i}}}{\sum_{\mathrm{i}=1}^{\mathrm{N}} n_{\mathrm{i}}}
$$

Average particle diameters in weight $D_{\mathrm{w}}$ (Equation (6)):

$$
D_{\mathrm{w}}=\frac{\sum_{\mathrm{i}=1}^{\mathrm{N}} n_{\mathrm{i}} D_{\mathrm{i}}^{2}}{\sum_{\mathrm{i}=1}^{\mathrm{N}} n_{\mathrm{i}} D_{\mathrm{i}}}
$$

Average particle diameters in volume $D_{\mathrm{v}}$ (Equation (7)):

$$
D_{\mathrm{v}}=\frac{\sum_{\mathrm{i}=1}^{\mathrm{N}} n_{\mathrm{i}} D_{\mathrm{i}}^{4}}{\sum_{\mathrm{i}=1}^{\mathrm{N}} n_{\mathrm{i}} D_{\mathrm{i}}^{3}}
$$

Applying Equations (5)-(7) to the particle sizes in the core as well as near the surface of the specimen allowed for the determination of $D_{\mathrm{n}}, D_{\mathrm{w}}$ and $D_{\mathrm{v}}$ from the SEM-images. It can be clearly observed from Figure 3 and Table 3 that the average particle size of the dispersed phase increases with the intrinsic viscosity of the EPR phase, i.e. with increasing melt viscosity ratio between the phases. This is
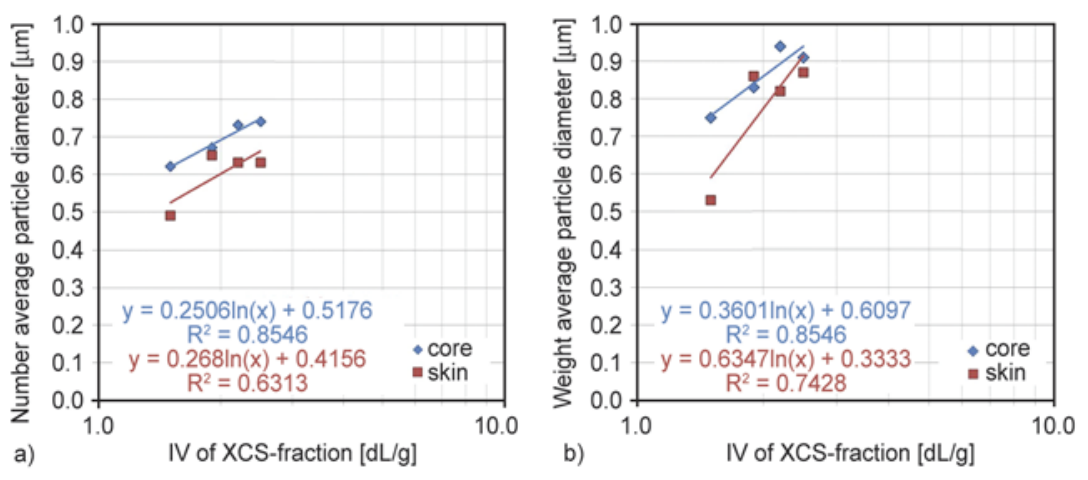

Figure 3. Average particle diameters by number (a), weight (b) and volume (c) as function of the intrinsic viscosity of the dispersed EPR phase (XCS fraction) determined for nucleated samples

Table 3. Average particle diameters of in-reactor nucleated materials (spherical particles assumed)

\begin{tabular}{|c|l|c|c|c|c|c|}
\hline \multicolumn{1}{|c|}{ Region } & \multicolumn{1}{|c|}{ Parameter } & Unit & IV1.5N & IV1.9N & IV2.2N & IV2.5N \\
\hline \multirow{4}{*}{ Core } & Number average particle diameter, $D_{\mathrm{n}}$ & $\mu \mathrm{m}$ & 0.62 & 0.67 & 0.73 & 0.74 \\
\cline { 2 - 8 } & Weight average particle diameter, $D_{\mathrm{w}}$ & $\mu \mathrm{m}$ & 0.75 & 0.83 & 0.94 & 0.91 \\
\cline { 2 - 8 } & Volume average particle diameter, $D_{\mathrm{v}}$ & $\mu \mathrm{m}$ & 1.06 & 1.25 & 1.32 & 1.21 \\
\hline \multirow{3}{*}{ Skin } & Number average particle diameter, $D_{\mathrm{n}}$ & $\mu \mathrm{m}$ & 0.49 & 0.65 & 0.63 & 0.63 \\
\cline { 2 - 8 } & Weight average particle diameter, $D_{\mathrm{w}}$ & $\mu \mathrm{m}$ & 0.53 & 0.86 & 0.82 & 0.87 \\
\cline { 2 - 8 } & Volume average particle diameter, $D_{\mathrm{v}}$ & $\mu \mathrm{m}$ & 0.67 & 1.39 & 1.27 & 1.38 \\
\hline
\end{tabular}



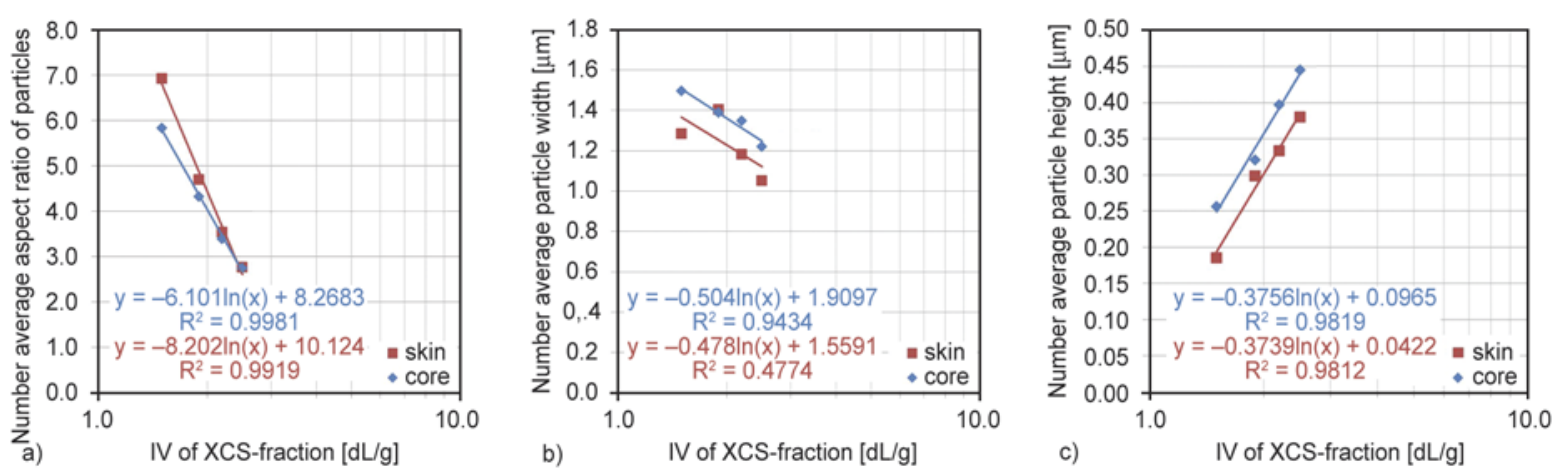

Figure 4. Average particle aspect ratio by number (a), particle height (b) and particle width (c) as function of the intrinsic viscosity of the dispersed EPR phase (XCS fraction) determined for nucleated samples

XCS and particle dimensions could be found (Figure 4). Only the particle width in the skin region of sample IV1.9N was not fitting into this correlation. A possible explanation for this outlier could be a more pronounced agglomeration of particles (compare Figure 1). However, a more in-depth analysis of the samples morphology in flow direction would be required to prove this assumption.

Plotting the number average aspect ratio versus the IV of the EPR phase (i.e. XCS) shows that the deformation of particles in processing is most pronounced for the sample IV1.5N and steadily decreases with increasing molecular weight of the rubber. On the other hand the area of particles is lowest for IV $1.5 \mathrm{~N}$ and almost linearly increases with the intrinsic viscosity (compare Figure 5). Furthermore, some significant changes in morphology along the specimen thickness were found. As expected, particles in the skin region showed a clearly higher orientation than in the core. This phenomenon was most pronounced for samples IV1.5N and IV1.9N. Only minor differences in particle deformation along the lateral direction were found in the case of IV $2.2 \mathrm{~N}$ and IV $2.5 \mathrm{~N}$ (compare Figure 5).

\subsection{Shrinkage}

Injection molded parts of crystalline polymers are known to exhibit a skin-core structure rather independent of the type of polymer. For impact modified PP, this effect was described by e.g. Karger-Kocsis and Csikai [17]. Taking into account this skin-core structure, Fujiyama and Kimura [6] claim that the shrinkage in flow direction is increasing with the crystalline skin layer thickness of injection molded plaques which in turn is influenced by flowability, molar mass distribution etc. Corresponding light microscopy investigations of samples IV $1.5 \mathrm{~N}$ to IV2.5N did not show any change in skin layer thickness.

It is difficult to link the shrinkage data to the particle size of the rubbery phase due to the differences in orientation of particles and the skin core structure of the samples. Just the morphology in the core was subsequently considered in order to simplify the analysis. Applying this simplification, an increase in shrinkage with increasing IV of XCS and particle size was found. This shows that shrinkage is linked to the molecular weight of the dispersed phase and viscosity ratio between rubber and matrix respectively. However, the almost identical average particle area of sample IV2.2N and IV2.5N but significantly different shrinkage results (Figure 6) indicate that not only the size but also the shape of particles has a decisive influence on the shrinkage of heterophasic systems. Therefore, the actual particle dimensions were linked to shrinkage instead of the particle area. As already mentioned above, the particle area and particle aspect ratio were used to calculate the number average height and width of the dispersed phase. Comparing this data to the shrinkage of the samples resulted in a very nice fit of data (Figure 7).

The nucleation effect was only evident for the shrinkage perpendicular to the flow direction. Generally, the shrinkage of the non-nucleated samples was approximately $0.1 \%$ lower than for the nucleated materials. The shrinkage in flow direction displayed no significant difference between non-nucleated and nucleated compositions. As the nucleation only marginally affects the morphology of the dispersed phase, this can be assumed to reflect the influence of the matrix crystallinity on shrinkage. 

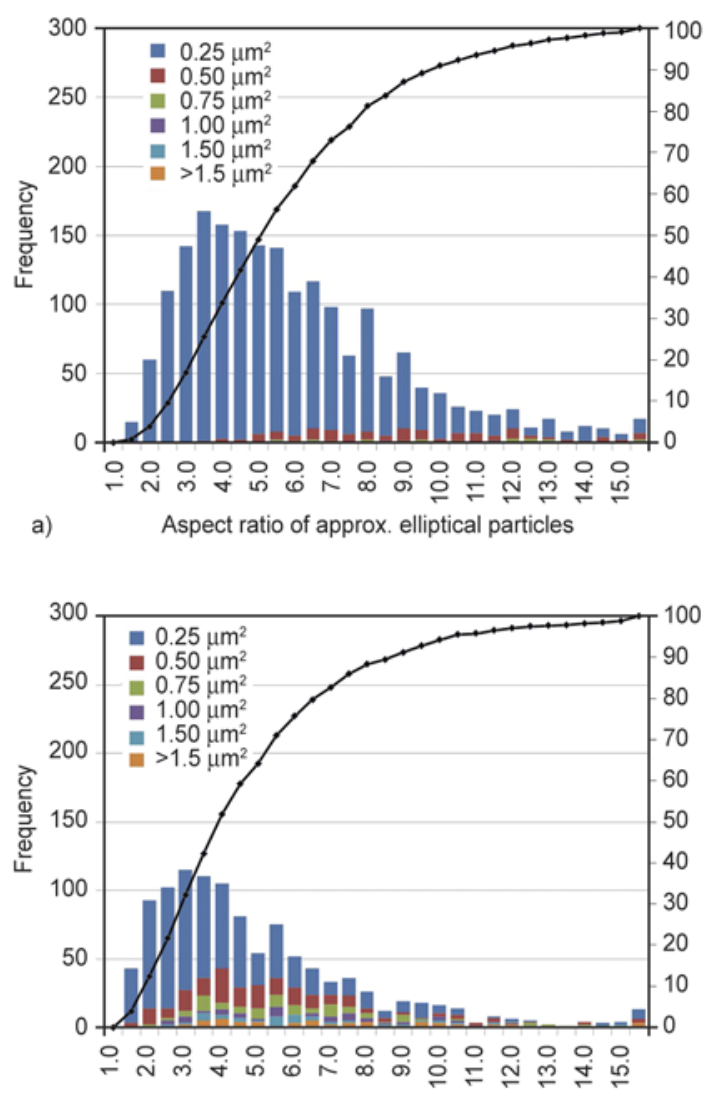

b)

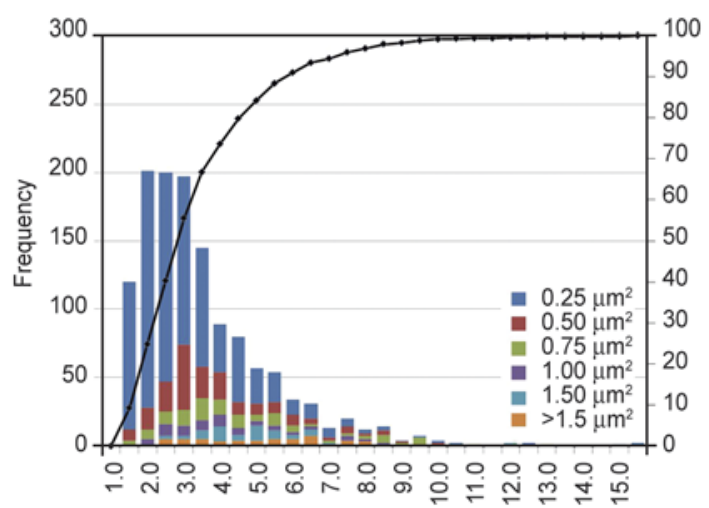

c)

Aspect ratio of particles

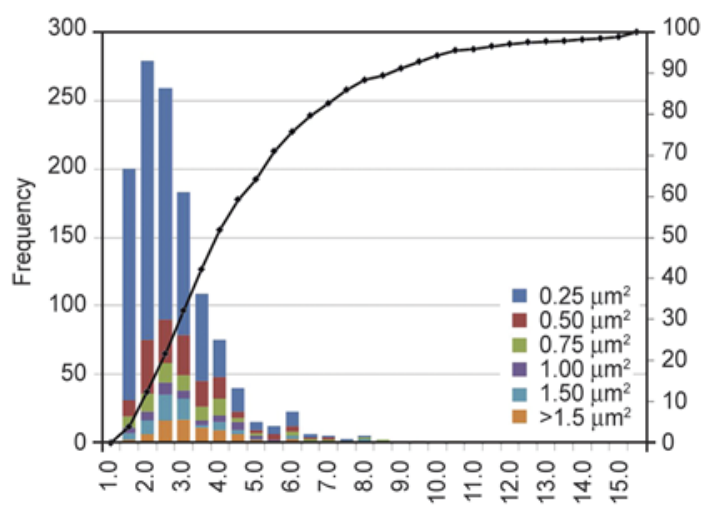

d)

Aspect ratio of particles

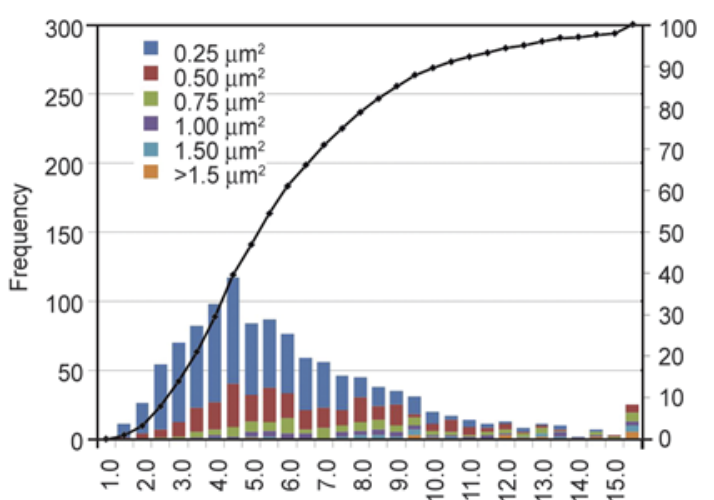

ङ

e)

Aspect ratio of approx. elliptical particles

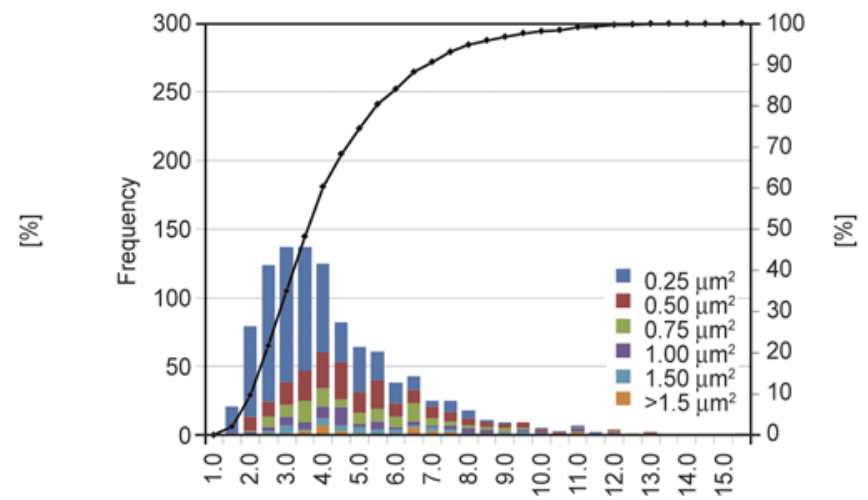

f)

Aspect ratio of particles

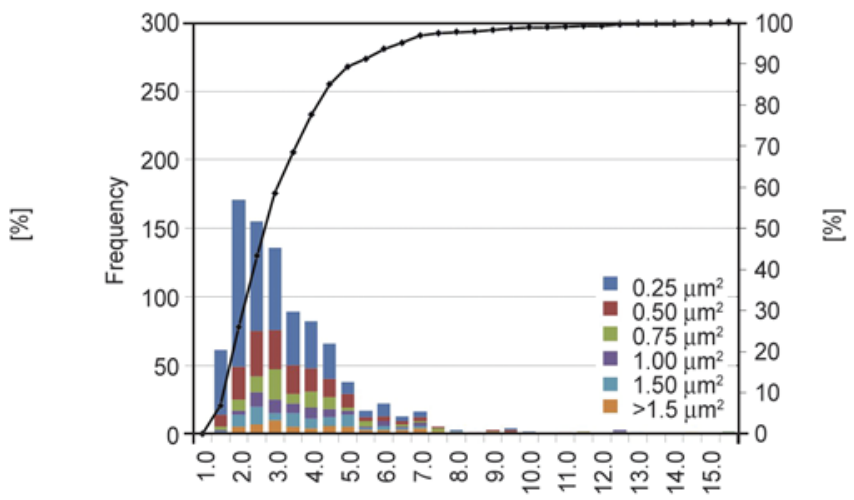

g) Aspect ratio of particles

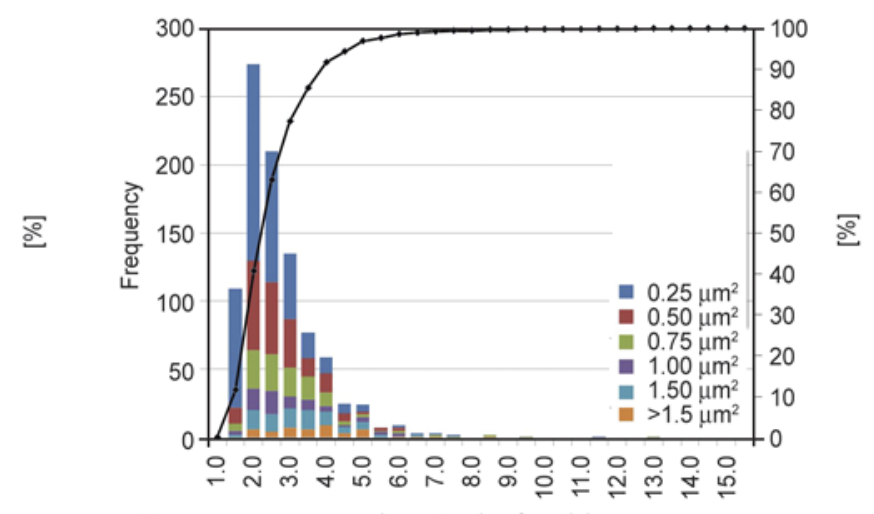

h)

Figure 5. Particle size distribution in the skin layer $(\mathrm{a}-\mathrm{d})$ and core region $(\mathrm{e}-\mathrm{h})$; IV(XCS) 1.5-1.9-2.2-2.5 from top to bottom 


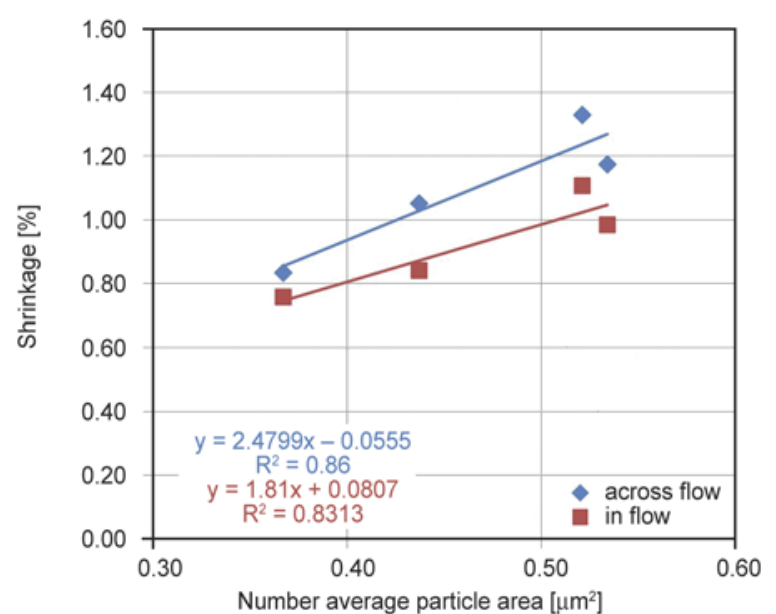

Figure 6. Correlation between shrinkage and number average particle area

\subsection{Coefficient of linear thermal expansion (CLTE)}

The CLTE was determined on specimens cut from injection molded test bars (in flow direction). These bars have a different geometry and are molded under different conditions than the shrinkage plates. The morphology determined from the latter can therefore only give a rough indication on the influence of dispersed phase morphology on CLTE. SEM investigations of the CLTE specimen would be required to get a more precise correlation. In lack of morphology data for these specimens CLTE was linked to the intrinsic viscosity of the EPR phase resp. XCS only. Similarly to the shrinkage cases, an increase in dimensional change with increasing IV of XCS was observed (Figure 8).

Due to their higher crystallinity, nucleated materials showed an approximately $15 \mu \mathrm{m} \cdot\left(\mathrm{m}^{-1} \cdot \mathrm{K}^{-1}\right)$ lower CLTE than the corresponding non-nucleated samples. The mobility of polymer chains in a crystal lattice is much more constrained than in amorphous regions. Hence, the volume increase upon heating

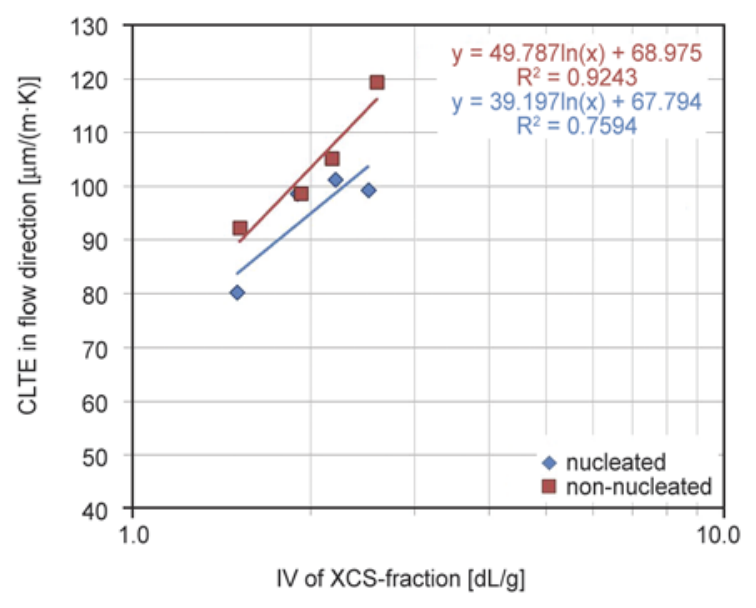

Figure 8. CLTE of the nucleated and non-nucleated materials in relation to the IV of the XCS-fraction (related to melt viscosity of the EPR phase)

and thermal expansion respectively is less for crystalline regions than for amorphous (at least for temperatures above the glass transition and below the melting of the crystals).

\section{Conclusions}

In the current investigation, the shrinkage of injection molded plates from reactor based PP/EPR blends with a high EPR-content of about $30 \mathrm{wt} \%$ and identical EPR composition were evaluated. Scanning Electron Microscopy (SEM) investigations of the polymers showed that the melt viscosity of the dispersed EPR phase, represented by the intrinsic viscosity of XCS fraction, significantly affects the size and distribution of EPR particles. This is in line with theory and was reported by a number of research groups (compare [17-22] and [25-28]). Unlike in previous studies, the particles' cross sections were not considered to be circular but taken to be elliptically shaped as a result of the orientation in the processing step. Therefore, the average particle diameter was not used in the evaluation of the morphol-
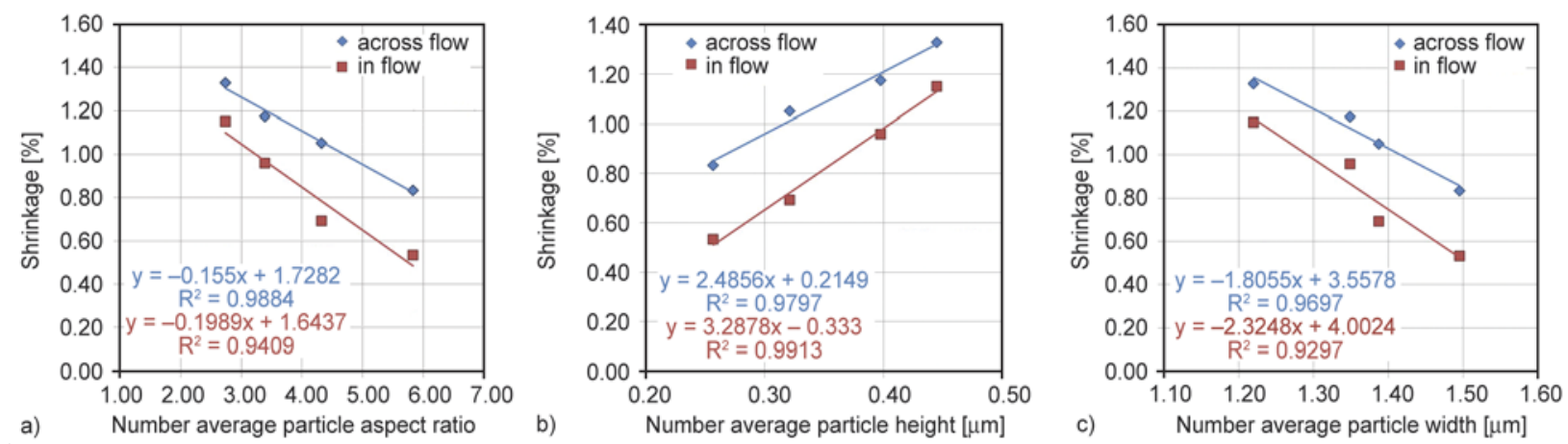

Figure 7. Shrinkage as a function of the number average particle aspect ratio (a), particle height (b) and particle width (c) 
ogy of the materials. Instead, the width and height, the aspect ratios as well as the areas of the particles were considered. It was shown that an increase in molecular weight of the EPR is accompanied by an increase in particle size and a decrease in the particles aspect ratio, i.e. a reduced deformation of the particles in the molding step. This coarsening of the phase morphology resulted in an increase in shrinkage and CLTE with the molecular weight of the EPR phase.

From the comparison of nucleated and non-nucleated materials it was found that alpha-nucleation increases the shrinkage across flow direction by about $0.1 \%$ while it hardly influences the shrinkage in the flow direction. This increase in shrinkage is a consequence of the higher crystallinity of the nucleated sample. At similar processing conditions, nucleation of PP leads to an increase in the molding shrinkage. The opposite is true for the CLTE.

\section{Acknowledgements}

The authors want to thank Renate Eckmayr and Gottfried Kandioller of Borealis Polyolefine $\mathrm{GmbH}$ in Linz, Austria for polymerising the materials of this study and preparing the excellent SEM images, respectively. Furthermore, we want to thank Markus Gahleitner, Senior Group Expert PP at Borealis, for his support and expertise in the interpretation and evaluation of collected data. Finally, a special thanks to the staff of the analytical and physical laboratory at Borealis in Linz for fractionating and characterizing the model materials.

\section{References}

[1] Fischer J. M.: Handbook of molded part shrinkage and warpage. William Andrew, New York (2003).

[2] Zoller P.: The pressure-volume-temperature properties of three well-characterized low-density polyethylenes. Journal of Applied Polymer Science, 23, 10571061 (1979).

DOI: $10.1002 /$ app.1979.070230410

[3] Jansen K. M. B.: Measurement and prediction of anisotropy in injection moulded PP products. International Polymer Processing, 13, 309-317 (1998). DOI: $10.3139 / 217.980309$

[4] Kwon K., Isayev A. I., Kim K. H., van Sweden C.: Theoretical and experimental studies of anisotropic shrinkage in injection moldings of semicrystalline polymers. Polymer Engineering and Science, 46 712-728 (2006).

DOI: $10.1002 /$ pen.20546
[5] Pomerleau J., Sanschagrin B.: Injection molding shrinkage of PP: Experimental progress. Polymer Engineering and Science, 46, 1275-1283 (2006).

DOI: $10.1002 /$ pen.20595

[6] Fujiyama M., Kimura S.: Effect of molecular parameters on the shrinkage of injection-molded polypropylene. Journal of Applied Polymer Science, 22, 12251241 (1978).

DOI: 10.1002/app.1978.070220506

[7] Fujiyama M., Kitajima Y., Inata H.: Structure and properties of injection-molded polypropylenes with different molecular weight distribution and tacticity characteristics. Journal of Applied Polymer Science, 84, 2142-2156 (2002).

DOI: $10.1002 / a p p .10372$

[8] Pantani R., Titomanlio G.: Description of PVT behavior of an industrial polypropylene-EPR copolymer in process conditions. Journal of Applied Polymer Science, 81, 267-278 (2001).

DOI: $10.1002 / a p p .1438$

[9] Shelesh-Nezhad K., Taghizadeh A.: Shrinkage behavior and mechanical performances of injection molded polypropylene/talc composites. Polymer Engineering and Science, 47, 2124-2128 (2007).

DOI: $10.1002 /$ pen.20940

[10] Prashantha K., Soulestin J., Lacrampe M. F., Lafranche E., Krawczak P., Dupin G., Claes M.: Taguchi analysis of shrinkage and warpage of injection-moulded polypropylene/multiwall carbon nanotubes nanocomposites. Express Polymer Letters, 3, 630-638 (2009).

DOI: 10.3144/expresspolymlett.2009.79

[11] Qi G-Q., Xu Y-J., Yang W., Xie B-H., Yang M-B.: Injection molding shrinkage and mechanical properties of polypropylene blends. Journal of Macromolecular Science Part B: Physics, 50, 1747-1760 (2011). DOI: $10.1080 / 00222348.2011 .583798$

[12] Ono M., Washiyama J., Nakajima K., Nishi T.: Anisotropic thermal expansion in polypropylene/poly (ethylene-co-octene) binary blends: Influence of arrays of elastomer domains. Polymer, 46, 4899-4908 (2005). DOI: $10.1016 /$ j.polymer.2005.03.098

[13] Ono M., Nakajima K., Nishi T.: Study on thermal expansion in injection-molded isotactic polypropylene and thermoplastic elastomer blends. Journal of Applied Polymer Science, 107, 2930-2943 (2008).

DOI: $10.1002 / a p p .27192$

[14] Spencer M. W., Paul D. R.: Modeling the mechanical and thermal expansion behavior of TPO-based nanocomposites. Polymer, 52, 4910-4919 (2011). DOI: 10.1016/j.polymer.2011.08.042

[15] Menyhárd A., Gahleitner M., Varga J., Bernreitner K., Jääskeläinen P., Øysæd H., Pukánszky B.: The influence of nucleus density on optical properties in nucleated isotactic polypropylene. European Polymer Journal, 45, 3138-3148 (2009).

DOI: $10.1016 /$ j.eurpolymj.2009.08.006 
[16] Gahleitner M., Grein C., Kheirandish S., Wolfschwenger J.: Nucleation of polypropylene homo- and copolymers. International Polymer Processing, 26, 2-20 (2011).

[17] Karger-Kocsis J., Csikai I.: Skin-core morphology and failure of injection-molded specimens of impact-modified polypropylene blends. Polymer Engineering and Science, 27, 241-253 (1987).

[18] Paulik C. E., Neiß1 W.: Phase structure and morphology: Designing a new class of heterophasic PP copolymers. Technical Papers of the Annual Technical Conference- Society Of Plastics Engineers Incorporated, 2, 2565-2570 (1998).

[19] Grein C., Bernreitner K., Hauer A., Gahleitner M., Neiß1 W.: Impact modified isotatic polypropylene with controlled rubber intrinsic viscosities: Some new aspects about morphology and fracture. Journal of Applied Polymer Science, 87, 1702-1712 (2003).

DOI: 10.1002/app.11696

[20] Premphet K., Paecharoenchai W.: Quantitative characterization of dispersed particle size, size distribution, and matrix ligament thickness in polypropylene blended with metallocene ethylene-octene copolymers. Journal of Applied Polymer Science, 82, 2140-2149 (2001).

DOI: 10.1002/app.2060

[21] Doshev P., Lach R., Lohse G., Heuvelsland A., Grellmann W., Radusch H-J.: Fracture characteristics and deformation behavior of heterophasic ethylene-propylene copolymers as a function of the dispersed phase composition. Polymer, 46, 9411-9422 (2005).

DOI: $10.1016 /$ j.polymer.2005.07.029
[22] Doshev P., Lohse G., Henning S., Krumova M., Heuvelsland A., Micheler G., Radusch H-J.: Phase interactions and structure evolution of heterophasic ethylenepropylene copolymers as a function of system composition. Journal of Applied Polymer Science, 101, 2825-2837 (2006).

DOI: 10.1002/app.22921

[23] Wu S.: Formation of dispersed phase in incompatible polymer blends: Interfacial and rheological effects. Polymer Engineering and Science, 27, 335-343 (1987). DOI: $10.1002 /$ pen.760270506

[24] Serpe G., Jarrin J., Dawans F.: Morphology-processing relationships in polyethylene-polyamide blends. Polymer Engineering and Science, 30, 553-565 (1990). DOI: 10.1002/pen.760300908

[25] Mighri F., Huneault M. A., Ajji A., Ko G. H., Watanabe F.: Rheology of EPR/PP blends. Journal of Applied Polymer Science, 82, 2113-2127 (2001).

DOI: 10.1002/app.2057

[26] Kock C., Gahleitner M., Schausberger A., Ingolic E.: Polypropylene/polyethylene blends as models for highimpact propylene-ethylene copolymers, Part 1: Interaction between rheology and morphology. Journal of Applied Polymer Science, 128, 1484-1496 (2013). DOI: 10.1002/app.38289

[27] Abramhoff M. D., Magalhães P. J., Ram S. J.: Image processing with ImageJ. Biophotonics International, 11, 36-42 (2004).

[28] Grein C., Gahleitner M., Knogler B., Nestelberger S.: Melt viscosity effects in ethylene-propylene copolymers. Rheologica Acta, 46, 1083-1089 (2007).

DOI: $10.1007 / \mathrm{s} 00397-007-0200-0$ 